\title{
Pacemaker mode selection and survival: a plea to apply the principles of evidence based medicine to cardiac pacing practice
}

Industry sources estimate that more than 440000 permanent pacemakers were implanted worldwide in 1995, at a cost of several billion dollars. In industrialised countries, sick sinus syndrome is the implant diagnosis in approximately half of all cases, and atrioventricular block constitutes the majority of the remaining cases. Other diagnoses such as neurocardiogenic syncope account for a relatively small number of implants. ${ }^{1}$

Current technology permits the selection of ventricular (single chamber) or atrial based (dual chamber and single chamber) systems for pacemaker recipients. At present, most atrial based systems implanted are dual chamber pacemakers. Single chamber ventricular pacemakers are less expensive, easier and faster to implant, less subject to lead malfunction, and more long lived than dual chamber devices. However, ventricular pacing is associated with loss of atrioventricular synchrony. In occasional ventricularly paced patients, loss of atrioventricular synchrony may lead to the pacemaker syndrome, a condition which may require surgical upgrade to dual chamber pacing. Dual chamber pacemakers permit maintenance of atrioventricular synchrony. However, dual chamber devices are more expensive, and more complex to implant and follow up. They are subject to malfunction in two leads instead of one, and they generally have a shorter battery life than do ventricular pacemakers.

These counterbalancing risks and benefits have led to a state of clinical equipoise. Randomised trial methodology must be applied to fill an important gap in clinical knowledge, and rationalise mode selection for all pacemaker recipients.

\section{Major retrospective studies}

Retrospective studies have provided an attractive hypothesis-that atrial based pacing, by preserving atrioventricular synchrony, prevents heart failure, prevents atrial fibrillation, reduces the incidence of stroke, and reduces mortality. However, the major retrospective studies are uniformly flawed and must be considered to be hypothesis generating rather than conclusive. There are many such studies and three of the best known and larger ones are analysed here.

Rosenqvist and coworkers ${ }^{23}$ opened the door to speculation that atrial based pacing was associated with improved patient outcomes. In 1984, and again in 1988, they reported on patients implanted with VVI or AAI pacemakers for sinus node dysfunction in two Swedish hospitals during the period October 1979 to December 1983. In one hospital, pacemaker patients were evaluated with an atrial pacing test. If atrioventricular conduction was intact, patients received an AAI pacemaker. In the other hospital, all patients received a VVI pacemaker, and an atrial pacing test was not performed. Follow up at four years showed that the incidence of atrial fibrillation was $47 \%$ for the
VVI group and $6.7 \%$ for the AAI group ( $P<0.001)$. Congestive heart failure and death were significantly less frequent in the AAI group (heart failure $15 \%$; death $8 \%$ ) than in the VVI group (heart failure $37 \%$; death $23 \%$ ) $(\mathrm{P}<0.001$ and $\mathrm{P}<0.005$, respectively). However, a careful analysis of this study reveals multiple potential sources of bias that might have had the effect of confounding the interpretation of the data.

Pacing mode was selected solely on the hospital that patients attended to receive their pacemakers. Subtle but systematic biases in symptoms and diagnoses might have affected hospital selection by patients, and selection of pacing by clinicians. AAI paced patients, not VVI patients, had "passed" an atrial pacing test prior to selection for AAI mode. Atrioventricular and intraventricular conduction disturbances may signify more severe underlying cardiac disease, and these patients were systematically excluded from the AAI group, but not from the VVI group. Furthermore, the fate of the patients rejected for atrial pacing after failing the atrial pacing test is not known. Thus, there is ample reason to suspect that a selection bias favouring less sick patients receiving AAI pacemakers may account for at least part of the clinical differences between groups.

We reported a retrospective analysis of 36312 pacemaker recipients aged 65 years or older. ${ }^{4}$ Patients were selected as a random sample of all Medicare patients who underwent initial pacemaker implantation from 1988-90 in the United States. Pacemaker mode selection was by attending physician choice. Mortality at one year in dual chamber paced patients $(13 \cdot 7 \%)$ was significantly lower than in VVI paced patients $(18.3 \%, \mathrm{P}<0.001)$ (fig). A Cox proportional hazards analysis demonstrated that pacing mode was an independent predictor of survival (odds ratio $0 \cdot 82$ ). Careful analysis of this large dataset reveals the extent and depth of the selection bias inherent in the clinical choice of pacemaker mode and type. Patient characteristics independently associated with dual chamber pacemaker selection included younger age, male sex, higher socioeconomic status, atrioventricular block, no history of atrial fibrillation, absence of peripheral vascular disease, and presence of fewer non-cardiac comorbid conditions. Dual chamber devices also were more likely to be implanted in hospitals that were urban, privately owned, over 500 beds in size, and had a cardiac catheterisation laboratory. Multivariate techniques can control for the identified sources of bias; however, other confounding variables that were uncoded and could not be controlled, such as living in a nursing home, dementia, or general debility, likely accounted for at least part of the clinical results.

In conclusion, abundant retrospective data paint a possibly overly optimistic picture of the potential benefits of dual chamber pacing. The results of the many published retrospective studies are not definitive because selection 

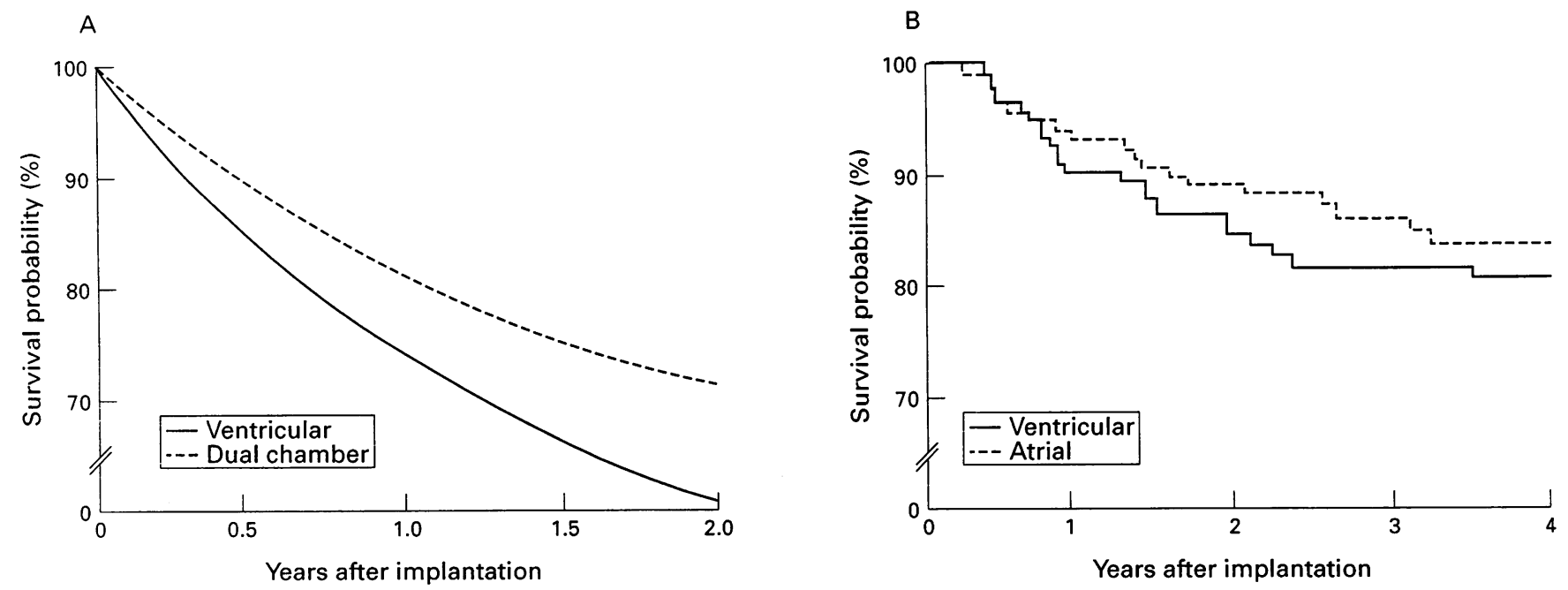

(A) Kaplan-Meier survival plots in a Medicare population paced VVI or DDD $(P<0.001)$. (Adapted from reference 4.) (B) Kaplan-Meier survival plots in patients randomised to VVI $(n=115)$ or $A A I(n=110)$ pacing (not significant). (Adapted from reference 5.$)$

bias coloured clinical decisions, and thus likely accounted for many of the more optimistic results.

\section{The first prospective study}

With this background, Andersen and coworkers ${ }^{5}$ published the first randomised trial of pacemaker mode selection in 225 patients with sinus node dysfunction. All patients who passed an initial screen for atrioventricular block were randomly assigned to receive AAI $(n=110)$ or VVI ( $\mathrm{n}=115)$ pacing. During a mean follow up of $2 \cdot 7$ years, the incidence of atrial fibrillation, stroke, or survival (fig) was not different between treatment groups. However, a combined endpoint of stroke plus peripheral embolism did show a significant difference favouring AAI pacing: six $(5 \%)$ in the AAI group compared with 20 $(17 \%)$ in the ventricular group $(P=0.005)$. Pacemaker syndrome requiring reoperation and upgrade to atrial based pacing was present in only two patients originally assigned to VVI.

This important first randomised pacemaker trial underscores the difficulties inherent in the interpretation of the previously presented retrospective clinical data, and in the design and interpretation of prospective trials. The retrospective analyses of pacing practice had led to expectations of decreased mortality in AAI paced patients. However, when randomisation was used to balance the treatment groups, no clear survival benefit was observed. Nevertheless, the correct interpretation of this seemingly negative effect on mortality also requires careful consideration of statistical power. Given the small size of the study (115 control patients) and the small number of events (25 control group deaths), a calculation of statistical power reveals that there was only a $19 \%$ likelihood of detecting a $30 \%$ decrease in AAI group mortality. Furthermore, to reach a statistical power of $90 \%$, there would have to be an expectation of a $71 \%$ reduction in AAI mortality, an extremely ambitious goal in modern times and with modern therapies. Consequently, this important study did not have enough statistical power to exclude a small or moderate, but important, survival benefit of atrial based pacing. Large scale randomised clinical trials with enough statistical power to provide a conclusive answer must be designed and performed, lest a significant therapeutic benefit of atrial based pacing be missed.

\section{Other small studies}

$\mathrm{We}^{67}$ have reported preliminary results of the Pacemaker Selection in the Elderly Trial. Preliminary analyses suggested interesting trends in clinical endpoints. However, this 400 patient study was designed to have adequate statistical power for a quality of life endpoint, and not for a mortality endpoint. Other small studies in progress (table 1) are also addressing important but secondary issues such as quality of life and the development of atrial fibrillation.

Due to considerations of statistical power, large trials are necessary to determine whether atrial based pacing improves survival.

\section{Need for definitive studies}

Randomised controlled trials are the premier tool currently in use to test treatment modalities. The results of

Table 1 Small studies of pacemaker selection

\begin{tabular}{|c|c|c|c|c|c|c|c|}
\hline Study & $\begin{array}{l}\text { Principal } \\
\text { investigator(s) }\end{array}$ & $\begin{array}{l}\text { Implant } \\
\text { diagnoses }\end{array}$ & $\begin{array}{l}\text { Number of } \\
\text { patients }\end{array}$ & $\begin{array}{l}\text { Primary } \\
\text { endpoint }\end{array}$ & Modes tested & $\begin{array}{l}\text { Status as of } \\
\text { October } 1996\end{array}$ & \\
\hline Andersen & Andersen & $\begin{array}{l}\text { Sinus node } \\
\text { dysfunction }\end{array}$ & 225 & $\begin{array}{l}\text { Mortality + } \\
\text { embolism }\end{array}$ & VVI $v$ AAI & Published $^{6}$ & \\
\hline Andersen & Andersen & $\begin{array}{l}\text { Sinus node } \\
\text { dysfunction }\end{array}$ & 200 & $\begin{array}{l}\text { LA and LV size } \\
\text { and function }\end{array}$ & AAIR $v$ DDDR & Enrolling & - \\
\hline PAC-A-TACH & Wharton & $\begin{array}{l}\text { Sinus node } \\
\text { dysfunction }\end{array}$ & 200 & Atrial fibrillation & VVIR $v$ DDDR & Follow up & \\
\hline PASE & Lamas, Orav, & All diagnoses & 407 & $\begin{array}{l}\text { Quality of life } \\
\text { (SF-36) }\end{array}$ & VVIR $v$ DDDR & Completed & \\
\hline RAMP & $\begin{array}{l}\text { Lamas, Orav, } \\
\text { Goldman }\end{array}$ & All diagnoses & 400 & $\begin{array}{l}\text { Quality of life } \\
\text { (SF-36) }\end{array}$ & $\mathrm{DDD} v \mathrm{DDDR}$ & Enrolling & \\
\hline STOP-AF & $\begin{array}{l}\text { Charles, Garratt, } \\
\text { Stafford }\end{array}$ & $\begin{array}{l}\text { Sinus node } \\
\text { dysfunction }\end{array}$ & 300 & $\begin{array}{l}\text { Recurrent atrial } \\
\text { fibrillation }\end{array}$ & $\begin{array}{l}\mathrm{VVI}(\mathrm{R}) v \mathrm{DDD}(\mathrm{R}) \\
\text { or AAI(R) }\end{array}$ & Enrolling & \\
\hline
\end{tabular}

LA, left atrium; LV, left ventricle; PAC-A-TACH, Pacemaker Atrial Tachycardia Trial; PASE, Pacemaker Selection in the Elderly; RAMP, Rate Modulated Pacing and Quality of Life; STOP-AF, Systematic Trial of Pacing for Atrial Fibrillation. 
Table 2 Large studies of pacemaker selection

\begin{tabular}{|c|c|c|c|c|c|c|}
\hline Study & $\begin{array}{l}\text { Principal } \\
\text { investigators }\end{array}$ & $\begin{array}{l}\text { Implant } \\
\text { diagnoses }\end{array}$ & $\begin{array}{l}\text { Number of } \\
\text { patients }\end{array}$ & $\begin{array}{l}\text { Primary } \\
\text { endpoint }\end{array}$ & Modes tested & $\begin{array}{l}\text { Status as of } \\
\text { October } \\
1996\end{array}$ \\
\hline CTOPP & Connolly, Kerr & All diagnoses & 2450 & Mortality & $\begin{array}{l}\mathrm{VVI}(\mathrm{R}) v \mathrm{AAI}(\mathrm{R}) \text { or } \\
\mathrm{DDD}(\mathrm{R})\end{array}$ & $\begin{array}{l}\text { Enrollment } \\
\text { complete }\end{array}$ \\
\hline MOST & $\begin{array}{l}\text { Lamas, Lee, } \\
\text { Goldman }\end{array}$ & $\begin{array}{l}\text { Sinus node } \\
\text { dysfunction }\end{array}$ & 2000 & $\begin{array}{l}\text { Mortality + } \\
\text { stroke }\end{array}$ & VVIR $v$ DDDR & Enrolling \\
\hline UKPACE & $\begin{array}{l}\text { Skehan, Camm, } \\
\text { deBono, Toff }\end{array}$ & $\begin{array}{l}\text { High grade AV } \\
\text { block }\end{array}$ & 2000 & Mortality & VVI or VVIR $v$ DDD & Enrolling \\
\hline
\end{tabular}

CTOPP, Canadian Trial of Physiologic Pacing; MOST, Mode selection Trial in Sinus Node Dysfunction; UKPACE, United Kingdom Pacing and Cardiovascular Events Trial.

such trials are generally accepted by clinicians and can be shown to lead to prompt changes in patient management strategies. ${ }^{8}$ Current data that suggest improved outcomes with atrial based pacing are inconclusive. Cost concerns because of more expensive DDD or DDDR generators and the need for an atrial lead, as well as generally shorter DDDR device longevity, may favour ventricular pacing. Furthermore, safety concerns constitute one of the more important costs of excessive technology. Patient safety issues such as those faced by recipients of the Telectronics Accufix (Engelwood, Colorado, USA) atrial lead ${ }^{9}$ render a blanket recommendation for dual chamber pacing in all pacemaker recipients with sinus rhythm impractical and scientifically unjustified. However, if randomised clinical trials demonstrate that atrial based pacing improves the clinical outcome of pacemaker recipients, then the global application of dual chamber technology to all eligible pacemaker patients would be medically sound and economically defensible. At present, there are several such studies in progress in the United Kingdom and North America (table 2), prospectively addressing the proper use of pacing technology. The eventual publications of the Canadian Trial of Physiologic Pacing (CTOPP), the Mode Selection Trial in Sinus Node Dysfunction (MOST), and the United Kingdom Pacing and Clinical
Events Trial (UK-PACE) will finally bring the benefits of evidence based medicine to the practice of cardiac pacing. The author acknowledges the statistical advice and assistance of John Orav.

Mount Sinai Medical Center,

GERVASIO ANTONIO LAMAS

4300 Alton Road,

Miami Beach, FL 33140, USA

e-mail: glamas@msmc.com

1 Bernstein AD, Parsonnet V. Survey of cardiac pacing in the United States in 1989. Am $\mathcal{F}$ Cardiol 1992;69:331-8.

2 Rosenqvist M, Brandt J, Schuller $\mathrm{H}$. Atrial versus ventricular pacing in sinus node disease: a treatment comparison study. Am Heart $\mathcal{f}$ 1986;111: 292-7.

3 Rosenqvist $\mathbf{M}$, Brandt J, Schuller $\mathbf{H}$. Long-term pacing in sinus node disease: effects of stimulation mode on cardiovascular morbidity and mortality. Am Heart f 1988;116:16-22.

4 Lamas GA, Pashos CL, Normand SLT, McNeil B. Permanent pacemaker selection in the elderly and subsequent survival in elderly Medicare pacemaker recipients. Circulation 1995;91:1063-9.

5 Andersen HR, Thuesen L, Bagger JP, Vesterlund T, Thomsen PEB. Prospective randomized trial of atrial versus ventricular pacing in sick sinus syndrome. Lancet 1994;344:1523-8.

6 Lamas GA, Stambler B, Mittleman R, Wilkoff B, Keim S, Brinker J, et al, for the PASE Investigators. Clinical events following DDDR versus VVIR the PASE Investigators. Clinical events following DDDR versus
pacing: results of a prospective trial [abstract]. $P A C E$ 1996;19:619A.

7 Stambler B, Ellenbogen K, Pinsky S, Lieberman EH, Mitchell G, Bush D, et al, for the PASE Investigators. Development of post-implant atrial fibet al, for the PASE Investigators. Development of post-implant atrial fria-
rillation (AFIB) during DDDR versus VVIR pacing in the PASE trial [abstract]. PACE 1996;19:214A

8 Lamas GA, Pfeffer MA, Hamm P, Jacobson K, Rouleau JL, Wertheimer J, et al, for the SAVE Investigators. The impact of clinical trials on the practice of cardiology. N Engl $¥ \mathrm{Med}$ 1992;327:241-7.

9 Brinker JA. Endocardial pacing leads: the good, the bad, and the ugly. PACE 1995;18:953-7. 